\title{
Herbal medicine from the perspective of type II diabetic patients and physicians: what is the relationship?
}

\author{
Aljawharah Alqathama ${ }^{1 *} \mathbb{D}$, Ghadeer Alluhiabi ${ }^{1}$, Halah Baghdadi ${ }^{1}$, Lujain Aljahani ${ }^{1}$, Ola Khan ${ }^{1}$, Sara Jabal ${ }^{1}$, \\ Shorooq Makkawi ${ }^{1}$ and Farah Alhomoud ${ }^{2}$
}

\begin{abstract}
Background: Diabetes mellitus (DM) is a major public health problem and one of the most challenging diseases worldwide. According to the World Health Organization (WHO), the Kingdom of Saudi Arabia (KSA) has the second highest rate of diabetes in the Middle East and seventh highest globally. Some diabetic patients may prefer to use alternative approaches such as herbal remedies to control their blood glucose level and this study aims to assess the prevalence of herbal usage and to evaluate users' and doctors' knowledge, attitudes and beliefs about herbal medicine as well as the patient/doctor relationship in this regard.
\end{abstract}

Method: A cross-sectional survey was conducted in several hospitals and medical centres in Makkah, KSA, between January and March 2019. Around 289 type II diabetic patients and 105 doctors were interviewed.

Results: We found that $68 \%$ of the participants were frequent consumers of herbal remedies, especially cinnamon, ginger and fenugreek. Patients' knowledge of herbal usage was mainly gleaned from family and friends as well as social media, and we found that many (71.4\%) did not bother to consult or inform their doctors about their choice to self-medicate with herbs. Patients had no concerns regarding the efficacy and safety of herbal usage use in diabetes, as around half of the participants believe that herbal medicine is effective (54\%) and safe (46\%) for treating symptoms of diabetes. Two-thirds of the doctors (66\%) routinely ask patients whether they use herbs for their condition. Although $25 \%$ of the doctors took a positive view of herbal medicine in relation to diabetes, others expressed concerns with the rise in herb use and want to see more attention paid to safety aspects.

Conclusion: The study concludes that herbal remedies are commonly used by diabetic patients and that a gap exists in the relationship between patients and doctors concerning the disclosure of herbal remedy use and views on its safety.

Keywords: Diabetes, Herbal medicine, Herbs, Patients, Physician, Prevalence, Knowledge, Belief, Attitude, Relationship

\section{Background}

Herbal medicine is a form of healthcare that comes under the category of complementary and alternative medicine (CAM) [1]. As defined by the US National Center for Complementary and Alternative Medicine, CAM is a group of heterogeneous medical and healthcare systems, substances, supplements and procedures that are not part of mainstream or conventional medicine [2] Any products originating from plants and consumed or applied to treat

\footnotetext{
* Correspondence: aaqathama@uqu.edu.sa

'Department of Pharmacognosy, Pharmacy College, Umm Al-Qura University, Makkah 21955, Saudi Arabia

Full list of author information is available at the end of the article
}

illness or maintain health belong to herbal medicine, which is part of CAM practice. It is one of the oldest documented forms of traditional medicine and has been found to be 5000 years old. However, scientific evidence is still lacking for its effectiveness [3].

In most countries, herbal medicines are commonly used among all healthcare systems [4]. According to the World Health Organization (WHO), in developing countries approximately $80 \%$ of the population have been found to be using this form of medicine for primary care such as those in Africa and Asia [5]. Similarly, nowadays herbal medicines are also in great demand in the developed world as interest in herbal medicine has soared 
over the last two decades [6]. In Europe, and the United States (US), around $75 \%$ (France) and $42 \%$ of the population respectively, were found to use herbal medicine at least once [7, 8]. Similar numbers have been seen in Middle Eastern countries such as Egypt (86\%) and the Kingdom of Saudi Arabia (KSA) (88\%). Therefore, herbal medicines have achieved high academic, industrial and economic interest due to their global prevalence $[9,10]$. CAM is also common in KSA, where herbs, honey, dietary products, prayer and cupping are widely used for medicinal purposes by the general public. Most of the existing studies were conducted in the Riyadh region, with very few in other areas, such as the west of KSA, which is known for its cultural diversity and would be a useful area for research [11].

Diabetes mellitus is among the most prevalent chronic diseases and is associated with high rates of morbidity and mortality [12]. WHO estimated that 347 million people worldwide were diagnosed with diabetes in 2013 and this figure is expected to double by 2030 [13]. Recently, WHO estimated 1.6 million deaths were directly linked to diabetes [14]. The majority of those who are affected are the middle-income populations living in Asia, Africa and South America [13]. Diabetes causes one death every $6 \mathrm{sec}$ with death cases (5 million), a rate higher than all deaths from human immunodeficiency virus (HIV) (1.5 million), tuberculosis (1.5 million) and malaria (0.6 million) combined. If left untreated, diabetes can lead to potential complications that include damage in organs such as the kidneys, heart, eyes, blood vessels and nerves [15].

Emerging data show that diabetic patients use CAM with varying degrees of success. About 2 to 3.6 million people use CAM in the USA to manage diabetic symptoms [13]. A Canadian study found that $44 \%$ of diabetic patients used over-the-counter supplements, compared to $31 \%$ patients who used alternative medication [16]. Similarly, in Australia it was found that $25 \%$ of diabetic patients had been using CAM in the 5 years between 2011 and 2015 [16]. In the US, herbal medicine use has increased by up to $380 \%$ [13]. Previous studies have revealed that diabetics tend to use herbal remedies to minimize dissatisfaction with conventional therapies. Another reason for using herbs is their concern about possible side effects caused by conventional therapies. This is because these patients believe that herbal remedies from natural sources are safer and more effective [15].

Past studies indicate that the beliefs and attitudes of healthcare providers about CAM vary greatly, from scepticism to strong support [17]. The literature review shows that healthcare professionals often demonstrate minimal formal education and little real knowledge of alternative medicine, and that there exists a significant gap between the high use of CAM by patients and acknowledgement or acceptance by healthcare professionals. Studies show that patients are reluctant to discuss their use of CAM with healthcare professionals $[17,18]$. With regard to diabetes treatment, there is a lack of studies investigating the patient/doctor relationship, as well as the attitudes and beliefs of healthcare professionals regarding herbal medicine in diabetic management. Therefore, the purpose of this study was to investigate the knowledge, attitudes and beliefs of diabetic patients and their physicians regarding herbal usage, as well as the nature of the patient/doctor relationship in terms of discussing this practice with patients.

\section{Methods}

\section{Study design and setting}

A descriptive, cross-sectional study design using structured predesigned questionnaires which were distributed among type II diabetic outpatients and doctors who are working or registered at all four government hospitals (Al Noor, Heraa, King Abdulaziz and King Faisal hospitals) and medical centres (13 centres) in Makkah, Saudi Arabia, was conducted for the period from January to March 2019.

\section{Sampling and recruitment strategies Justification of the chosen medical centres and representativeness}

A purposive sample was selected; all government hospitals registered at the Ministry of Health in Makkah Province which have endocrinology clinics were involved. Another sampling approach was also considered; a convenience sampling technique based on locating endocrinology clinics in medical centres distributed in several locations in Makkah (12 medical centres) was carried out.

\section{Sample size and recruiting patients and doctors}

For patients, all $\geq 18$ years old patients diagnosed with type II diabetes, not pregnant and who were able to take part were included and interviewed during their visits for follow-up care at endocrinology clinics/medical centres or for refill medications. The doctors in the sample included all endocrinologists who treated diabetic patients at hospitals where there was a department of Internal Medicine or an endocrinology clinic as well as doctors dealing with and giving follow-up treatment to diabetic patients in medical centres. Doctors in the Internal Medical department who do not deal with diabetic patients were excluded. Only diabetic type II patients and their doctors were verbally asked to participate after the study purpose was explained and they were provided with informed consent forms to sign before participation. The sample size was calculated using an online sample calculator (Raosoft). A single population proportion formula was used with the assumption of $95 \%$ 
confidence interval, 5\% margin of error, among 3,852, 000 diabetic patients in KSA as it was estimated by the International Diabetes Federation (IDF) [19]. Therefore, a total of 385 participants were required. However, due to time limitations in the sample hospitals, only 309 patients took part in this project. Due to the fact that it was difficult to obtain the number of registered endocrinologists in Internal Medicine departments and endocrinology clinics in the $\mathrm{MOH}$ in Makkah, the sample size was justified by the power of the study and finally adjusted for non-response/unintended error using the following statistical formula [20].

$$
n=\frac{\left(Z_{1-\beta}\right)^{2}[p(1-p)]}{E^{2}}
$$

A sample size of 105 can achieve more than $80 \%$ power with $20 \%$ non-response/unintended error rate.

\section{Study instrument}

A literature review was undertaken to develop both questionnaires to assess the prevalence of herbal usage and evaluate the knowledge, attitudes and beliefs of diabetic patients and their physicians regarding herbal medicine. After drafting the initial version of each questionnaire, the advisory group (i.e. pharmacy academic staff) were given these questionnaires to comment on the wording and the content, as per the requirements of the quality assessment. Comments and feedback were obtained and the final questionnaire was developed subsequently. The questionnaire was then piloted to five randomly chosen diabetic patients in one of the endocrinology clinics for feedback on wording, understanding, and ease of use. This helped to assess the feasibility of the questionnaire and acted as a method of face validity. Data collected from the pilot study were not included in the final analysis.

The questionnaires were constructed in several parts and covered knowledge, attitudes and beliefs regarding herbal usage. The patients' questionnaire was divided into two sections, the first focusing on patient-related information such as age, gender, living area, education level and presence of comorbidities, and the second investigated the prevalence of herbal product usage, knowledge of correct usage and disclosure of usage to their doctors. The questionnaire was conducted in Arabic for the patients' convenience. The doctors' questionnaire covered areas such as experience of and familiarity with herbal medicine, outcomes, attitudes to herbal remedies and how they deal with patients who use herbs.

In addition, to ensure reliability, which depends highly on the reproducibility of the collected data, we collected data using identical techniques at the same time to result in the same findings as mentioned previously [21].
To ensure this, steps were taken to follow the protocol for data collection. Questionnaires were distributed by the researchers, who were trained to interview participants at the diabetic clinics, to ensure they were received by the target populations. Moreover, data collection was performed on one single occasion and the collected data from all involved hospitals were subsequently analysed. To reduce the inadvertent bias in interpreting responses from open-ended questions, closed questions were chosen.

\section{Data processing and analysis}

The completed survey was processed and analysed using a quantitative procedure conducted using the statistical methods available in the Statistical Package for the Social Sciences (SPSS 26 software). The descriptive statistics were generated and possible relationships between different variables were assessed using a chi-square test.

\section{Ethical approval}

The study was approved by the Institutional Review Board (IRB) of the Ministry of Health, IRB number H02-K076-1811-063 on 12th December 2018. Written informed consent was obtained from all participants as stipulated by the IRB Committee.

\section{Results}

\section{Sample of type II diabetic patients}

A total of 309 questionnaires were distributed among diabetic patients; 298 completed the questionnaires, resulting in 298 responses (response rate $=96 \%$ ). The data show that $203(68.1 \%)$ of the diabetic participants used herbal medicines to manage their condition. Of those 188, (92.6\%) have comorbidities including hypo/ hypertension, cardiovascular diseases and others (see Table 1). The most commonly used herbs were cinnamon (23.1\%), ginger (19.2\%), fenugreek (9.3\%) and others such as garlic, onions, basil, black seed, fennel, peppermint, anise, cumin and parsley (Fig. 1). More than half of the participants stated that they used the herbs singly rather than as part of a mixture. These herbs listed in the study questionnaire are widely available in KSA and are well known to help in managing type II diabetes.

As shown in Table 1, it was found that more than half of herbal users were women $(n=123 ; 60.5 \%)$ and aged between 46 and 60 years $(n=112 ; 37.5 \%)$. The relationship between education and herbal use was measured, and it was found that $31.1 \%$ of herbal users had not completed their education and that $26.6 \%$ had received only primary education (Table 1). Statistical analysis was conducted using chi-square test; none of the patients' characteristics have shown a significant relation to the herbal consumption.

Those who were diagnosed with diabetes for over 10 years $(n=168 ; 56.4 \%)$ commonly utilized herbs for such 
Table 1 Demographics and comorbidities of type II diabetic patients

\begin{tabular}{|c|c|c|c|}
\hline \multirow[t]{2}{*}{ Variables } & \multirow{2}{*}{$\begin{array}{l}\text { Overall (n, } \\
\%)\end{array}$} & \multicolumn{2}{|c|}{ Herbal medicine use (n) } \\
\hline & & Yes $(n=203)$ & No $(n=95)$ \\
\hline \multicolumn{4}{|l|}{ Sex } \\
\hline Male & $128(43)$ & 80 & 48 \\
\hline Female & $170(57)$ & 123 & 47 \\
\hline \multicolumn{4}{|l|}{ Age } \\
\hline $18-45$ & $44(14.8 \%)$ & 31 & 131 \\
\hline $46-60$ & $153(51.3 \%)$ & 112 & 41 \\
\hline $61-75$ & $90(30.2 \%)$ & 54 & 36 \\
\hline More than 75 & $11(3.7 \%)$ & 6 & 5 \\
\hline \multicolumn{4}{|l|}{ Educational status } \\
\hline Illiterate & $100(33.6 \%)$ & 65 & 35 \\
\hline Primary & 77 (25.8\%) & 56 & 21 \\
\hline Intermediate & $35(11.7 \%)$ & 24 & 11 \\
\hline High school & 35 (11.7\%) & 23 & 12 \\
\hline University/college & $51(17.1 \%)$ & 35 & 16 \\
\hline \multicolumn{4}{|l|}{ Comorbidities } \\
\hline Hypo/hypertension & $155(55.8 \%)$ & 107 & 48 \\
\hline Heart disease & 47 (16.9\%) & 32 & 15 \\
\hline Other & $76(27.3 \%)$ & 49 & 27 \\
\hline \multicolumn{4}{|l|}{ Duration of disease } \\
\hline Less than 1 year & $11(3.7)$ & 7 & 4 \\
\hline $1-5$ year & $63(21.1)$ & 40 & 23 \\
\hline 6-9 year & $56(18.8)$ & 44 & 12 \\
\hline 10 years and more & $168(56.4)$ & 112 & 56 \\
\hline
\end{tabular}

conditions at least once a day $(n=112,55.1 \%)$. In terms of herb preparation methods, boiling the herbs (decoction) was the most common method of preparation, cited by approximately half of the herbal users $(n=98$; $40.7 \%)$, followed by soaking the herbs $(n=74,30.7 \%)$ and then either using the plant parts intact or as a powder (not shown in table).

Assessing patient sources of information (Table 2) about efficacy of herbs revealed that recommendation by family and friends was the most common $(n=156$; $50.6 \%)$, followed by social media $(n=73 ; 23.7 \%)$ and websites ( $n=49 ; 15.9 \%)$.

Patients' beliefs about the efficacy and safety of herbal remedies are illustrated in Table 3. Data show that more than one-half of the sample $(54.7 \%)$ either believe or strongly believe that herbal remedies are effective. In addition, only around $28 \%$ of the survey participants disagreed with the statement that herbs do not interact with their orthodox medication. There was a statistical significant relationship between the continuous use of herbs and the beliefs that the herbs would not interact with diabetic medication and that they would have a positive effect on controlling blood glucose levels $(p<$ $0.001, p$-value not shown in the table).

The participants were asked whether they discussed their herbal usage with their doctors and it was found that around 145 participants (71.4\%) (Table 4) did not consult their doctors about using herbs to control blood glucose levels. As shown in Table 4, being afraid of their doctor's disagreement or negative response was the least mentioned reason $(n=16 ; 11.0 \%)$. The main reason for non-disclosure of herb use by diabetic patients $(n=57$; $39.3 \%$ ) was not fear of disapproval by the medical establishment, but the fact that doctors rarely ask patients about their CAM use. A significant number of participants $(n=72 ; 49.6 \%)$ believed that doctors would not support herbal usage because of possible interactions with anti-diabetic medication, or the lack of reliable sources supporting herb efficacy (Table 4).

\section{Sample of physicians}

Of the 106 recruited doctors, 105 completed the questionnaire, representing a $99 \%$ response rate. The results
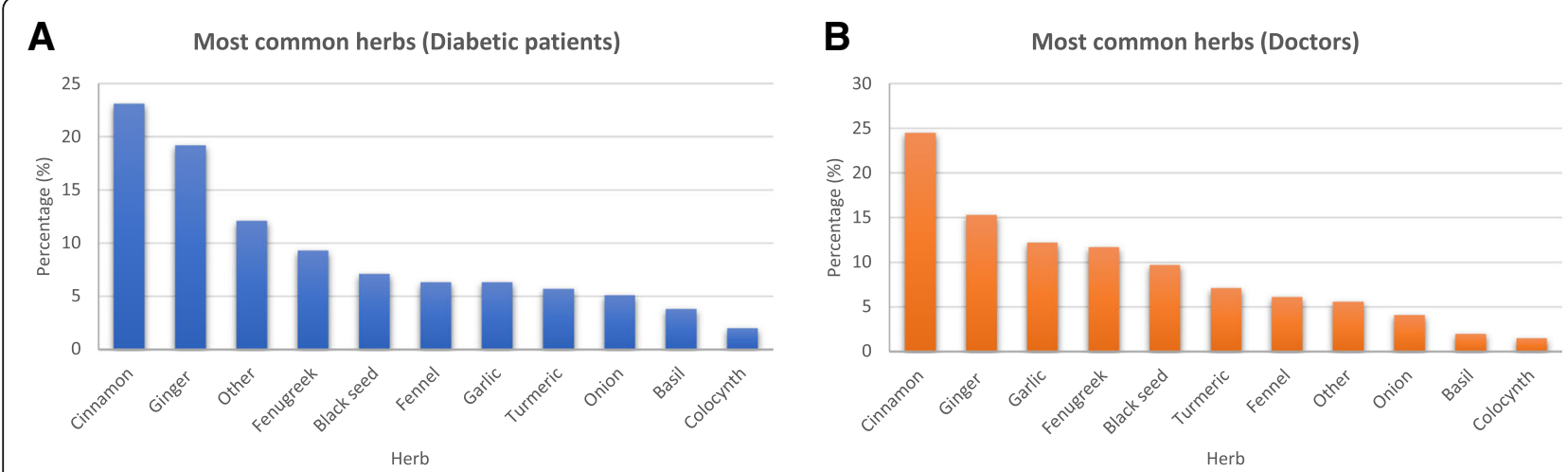

Fig. 1 The most frequently used herbs from the perspective of the diabetic population (a) and their doctors (b) 
Table 2 Source of herbal medicine information among herbal users

\begin{tabular}{lll}
\hline Source of information & Number & Percentage \\
\hline Family and friends & 156 & $50.6 \%$ \\
Social media & 73 & $23.7 \%$ \\
Healthcare providers' recommendation & 30 & $9.7 \%$ \\
Websites (internet) & 49 & $15.9 \%$ \\
\hline
\end{tabular}

show that 70 doctors $(66 \%)$ routinely asked their patients whether they were also using traditional herbal medicine alongside conventional medication. The majority of these doctors were fairly newly qualified and had less than 5 years' experience (Fig. 2).

Data illustrate that most of doctors $(n=74 ; 70.5 \%)$ (Table 5) believe that only a small percentage of diabetic patients are herbal users (0-25\%), but this contrasts with data obtained from the patients' category, which show significantly higher actual herbal use (68.1\%). The findings show that $37.1 \%$ of the doctors believed that herbal medicine had no effect in regulating blood glucose levels. However, 25.7\% $(n=27)$ indicated a belief that herbs could have a positive effect on blood glucose, while the rest were of the opinion that herbs could produce a negative effect by either reducing or elevating sugar levels. According to the doctors in the sample, the most commonly used herbs were cinnamon, ginger, garlic and fenugreek, which was in agreement with patient data.

Results analysis reveals that about 75 (71.4\%) of the doctors agree and strongly agree that patients used herbs to improve blood glucose levels, as well as other purposes such as treating other diseases $(n=59 ; 56.2 \%)$ and weight loss $(n=44 ; 41.9 \%)$ (Table 6$)$. In addition, data show that $64(61 \%)$ and $69(65.7 \%)$ of the doctors agree and strongly agree that they regularly asked their patients about herbal use in order to avoid herb side effects and herb-drug interactions with conventional treatment, respectively. It was also found that a high proportion of participants strongly believed that not all herbs are safe ( $\mathrm{n}=59 ; 56.2 \%)$. Furthermore, only a quarter of the doctors $(n=28 ; 26.7 \%)$ in the study used information based on scientific reports about herb uses in the practice, indicating that healthcare professionals should be encouraged to refer to scientifically reliable sources for their information on herbal medicine.
As shown in Table 6, 61 (58.1\%) of the doctors agreed that their awareness of herbal usage would have an effect on patient health. The study participants were asked whether they would refer their patients to a herbal medicine clinic if this was made available. More than a third of the participants $(n=36,34.3 \%)$ said they would not refer patients.

\section{Discussion}

Data revealed that two-thirds of the sample who suffer from diabetes were frequently using alternative therapies such as herbal medicine to control their glucose level and improve their health, in accordance with two previous studies conducted in Africa (Ethiopia, Nigeria) [22, 23]. However, two other studies conducted in Asia (Thailand) and the Middle East (KSA and UAE) showed that less than one-third of the sample were found to be using herbal medicine [24-26]. The differences between these numbers could be due to the discrepancy in the nature of these studies regarding the geographical location, levels of the population's dependency on herbal remedies, and because some of these studies included all the traditional CAM practices. This variability was also reported in a review mentioned in the literature of studies from nine countries, where studies of diabetic populations revealed a prevalence of alternative medicine use ranging from 17 to $72 \%$; however, herbal medicine is still an important feature of diabetes management worldwide [27]. Cinnamon and fenugreek were the most commonly used herbs not only in the KSA but also in other Arabic countries such as Bahrain, Oman, Iraq and Jordan [24]. This is because they are widely available in these countries due to the fact that all of these herbs thrive in their similar climates [28]. Similarly, in the USA and Canada, cinnamon was commonly used as well. In contrast, in Malaysia, bitter gourd and misai kucing were the most commonly used herbs; this difference is probably due to the differences in culture and geographical environment [29].

Older people (aged between 46 and 60) tend to take more herbs than younger people because they are more likely to seek alternative treatment options [22]. Similarly, in Alrowais' cross-sectional study which was conducted in four major hospitals in Riyadh, it was reported that patients aged between 60 and 75 years were the most frequent users of herbs for diabetic management

Table 3 Diabetic patients' knowledge and beliefs about herbal usage

\begin{tabular}{|c|c|c|c|c|c|}
\hline Statement & Strongly Agree & Agree & Neutral & Disagree & Strongly Disagree \\
\hline Patients believe that herbs have a good effect & $89(29.9 \%)$ & $74(24.8 \%)$ & $70(23.5 \%)$ & $24(8.1 \%)$ & $41(13.8 \%)$ \\
\hline Patients believe that herbs are safe & $81(27.2 \%)$ & $57(19.1 \%)$ & $93(31.2 \%)$ & $33(11.1 \%)$ & $34(11.4 \%)$ \\
\hline Patients believe that herbs do not interact with diabetic medications & $30(10.1 \%)$ & $35(11.7 \%)$ & $148(49.7 \%)$ & $52(17.4 \%)$ & $33(11.1 \%)$ \\
\hline Patients believe that it is possible to use herbs only & $7(2.3 \%)$ & $18(6.0 \%)$ & $42(14.1 \%)$ & $60(20.1 \%)$ & $171(57.4 \%)$ \\
\hline
\end{tabular}


Table 4 Patients' ability to disclose herbal usage to their doctors

\begin{tabular}{|c|c|c|}
\hline Have you told or consulted your doctor about using these herbs & Number & Percentage \\
\hline Yes & 58 & $28.6 \%$ \\
\hline No & 145 & $71.4 \%$ \\
\hline \multicolumn{3}{|c|}{ Reasons } \\
\hline \multicolumn{3}{|l|}{ For not telling your doctor } \\
\hline The doctor didn't ask me & 57 & $39.3 \%$ \\
\hline It is not necessary to inform the doctor about the herbs I use & 51 & $35.1 \%$ \\
\hline Other & 21 & $14.4 \%$ \\
\hline Possible doctor disagreement about herbal usage & 16 & $11.0 \%$ \\
\hline \multicolumn{3}{|l|}{ Why doctors do not support herbal usage } \\
\hline I do not know & 47 & $32.4 \%$ \\
\hline These plants may react with drugs and affect their effectiveness & 45 & $31.0 \%$ \\
\hline Lack of reliable scientific studies & 27 & $18.6 \%$ \\
\hline Herbs are not effective for diabetic management & 14 & $9.6 \%$ \\
\hline The difficulty in using herbs for diabetic management & 7 & $4.8 \%$ \\
\hline Other & 5 & $3.4 \%$ \\
\hline
\end{tabular}

[30]. This study agrees with the findings of Ching, Amaeze and Mekuria's studies related to gender differences, which showed that women were more likely to consume herbal remedies than men [22, 23, 29]. In a study by Shih et al. in Taiwan, patients aged $20-69$ years traditional Chinese medicine use frequency was significantly higher in women than in men across all age groups. According to their study, this is because women in these societies are the primary decision makers in family healthcare, and are more open to alternatives, tending to support CAM services more than men [31]. It was found here that $31 \%$ of herbal users had not

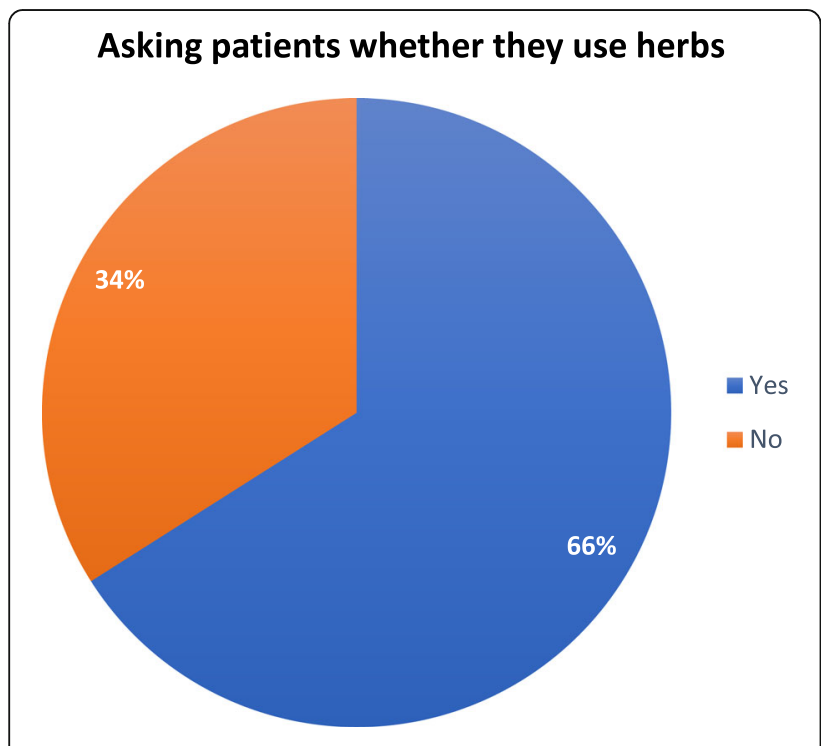

Fig. 2 Doctors' knowledge about herbal usage by diabetic patients completed their education and that $26.6 \%$ had only completed primary education. In Ilhan's study, which was conducted among herbal medicine users in Turkey, it was found that $58 \%$ of the users had received only primary education [32]. However, Alalami's study, conducted in the UAE, found that more highly educated patients (secondary and tertiary levels) were the most frequent users of herbs [25].

Regarding the source of information used by patients to obtain information on herbs, it was shown that the majority of participants in this study relied on their families and friends (50.6\%), social media (23.7\%) and the internet $(15.9 \%)$ as the main source of information on herbs used for diabetes. A study in Australia of pregnant women using CAM practice reported that nonprofessional sources of information were found to be influential in the studied population [33]. However, healthcare

Table 5 Doctors' knowledge about the percentage of diabetic herbal users and effect of herbs on them

\begin{tabular}{lll}
\hline What is the percentage of herbal users? & Number & Percentage \\
\hline $0-25$ & 74 & $70.5 \%$ \\
$26-50$ & 11 & $10.5 \%$ \\
$51-75$ & 1 & $1.0 \%$ \\
$76-100$ & 19 & $18.1 \%$
\end{tabular}

What is the effect of herbs on blood glucose level

\begin{tabular}{lll} 
No effect & 39 & $37.1 \%$ \\
Positive effect by improving glucose level & 27 & $25.7 \%$ \\
Negative effect by raising glucose level & 8 & $7.6 \%$ \\
Negative effect by reducing glucose level & 8 & $7.6 \%$ \\
\hline
\end{tabular}


Table 6 Doctors' beliefs and attitudes towards herbal medicine

\begin{tabular}{|c|c|c|c|c|c|}
\hline Statement & $\begin{array}{l}\text { Strongly } \\
\text { Agree }\end{array}$ & Agree & Neutral & Disagree & $\begin{array}{l}\text { Strongly } \\
\text { Disagree }\end{array}$ \\
\hline Patients use herbs to improve blood glucose level & $21(20.0 \%)$ & $\begin{array}{l}54 \\
(51.4 \%)\end{array}$ & $\begin{array}{l}23 \\
(21.0 \%)\end{array}$ & $6(5.7 \%)$ & $1(1.0 \%)$ \\
\hline Patients use herbs to treat other disease & $13(12.4 \%)$ & $\begin{array}{l}46 \\
(43.8 \%)\end{array}$ & $\begin{array}{l}37 \\
(35.2 \%)\end{array}$ & $7(6.7 \%)$ & $2(1.9 \%)$ \\
\hline Patients use herbs to lose weight & $8(7.6 \%)$ & $\begin{array}{l}36 \\
(34.3 \%)\end{array}$ & $\begin{array}{l}38 \\
(36.2 \%)\end{array}$ & $\begin{array}{l}19 \\
(18.1 \%)\end{array}$ & $4(3.8 \%)$ \\
\hline I ask patients about herbal usage to avoid side effects & $26(24.8 \%)$ & $\begin{array}{l}38 \\
(36.2 \%)\end{array}$ & $\begin{array}{l}26 \\
(24.8 \%)\end{array}$ & $\begin{array}{l}11 \\
(10.5 \%)\end{array}$ & $4(3.8 \%)$ \\
\hline I ask patients about herbal usage to avoid herb-drug interaction & $29(27.6 \%)$ & $\begin{array}{l}40 \\
(38.1 \%)\end{array}$ & $\begin{array}{l}23 \\
(21.9 \%)\end{array}$ & $10(9.5 \%)$ & $3(2.9 \%)$ \\
\hline Not all herbs are safe for diabetic patients & $59(56.2 \%)$ & $\begin{array}{l}26 \\
(24.8 \%)\end{array}$ & $\begin{array}{l}12 \\
(11.4 \%)\end{array}$ & $3(2.9 \%)$ & $5(4.8 \%)$ \\
\hline I recommend herbs for diabetic patients based on scientific information & $7(6.7 \%)$ & $\begin{array}{l}21 \\
(20.0 \%)\end{array}$ & $\begin{array}{l}39 \\
(37.1 \%)\end{array}$ & $\begin{array}{l}22 \\
(21.0 \%)\end{array}$ & $16(15.2 \%)$ \\
\hline $\begin{array}{l}\text { I recommend herbs for diabetic patients based on patients' previous } \\
\text { experiences }\end{array}$ & $2(1.9 \%)$ & $\begin{array}{l}11 \\
(10.5 \%)\end{array}$ & $\begin{array}{l}31 \\
(29.5 \%)\end{array}$ & $\begin{array}{l}35 \\
(33.3 \%)\end{array}$ & $26(24.8 \%)$ \\
\hline Doctor's awareness about herbal usage reflects positively on patient's health & $27(25.7 \%)$ & $\begin{array}{l}34 \\
(32.4 \%)\end{array}$ & $\begin{array}{l}21 \\
(20.0 \%)\end{array}$ & $\begin{array}{l}15 \\
(14.3 \%)\end{array}$ & $8(7.6 \%)$ \\
\hline I would refer diabetic patients to a herbal medicine clinic if available & $13(12.4 \%)$ & $\begin{array}{l}20 \\
(19.0 \%)\end{array}$ & $\begin{array}{l}36 \\
(34.3 \%)\end{array}$ & $\begin{array}{l}25 \\
(23.8 \%)\end{array}$ & $11(10.5 \%)$ \\
\hline
\end{tabular}

providers were the least likely source to be used, which was in line with one previous study conducted in Ethiopia [23].

Our study findings were in line with one previous study exploring the knowledge, attitude and practice (KAP) of CAM therapies among patients with type II diabetes [34]; both studies showed that more than onehalf of the participants believed that herbal medicine products have remarkably higher efficacy in controlling blood glucose levels and a wider safety window. This could be an indicator for potential plant toxicity unawareness by users that might be caused by improper use or handling. Half of the diabetic patients in our study did not consult their doctors before starting to use herbal remedies, which was consistent with another previous study which reported that $68 \%$ of participants had not disclosed their herbal usage to their doctors [35]. Reasons reported by previous studies for such lack of disclosure were: doctors rarely ask patients about their herbal use, as reported here [36], or due to an anticipated negative response [23]. The absence of clear communication between patients and healthcare providers may have a potentially serious effect on patient health and outcomes as patients may experience plant toxicity due to improper use, expected and unexpected side effects, and herb-drug interaction with hypoglycaemic drugs.

Doctors in our study believed that the majority of patients are non-herb users, but this is not consistent with patient response. This indicates the presence of gap in communication between patients and doctors. Solutions such as educational intervention may be effective, whereby doctors would be adequately equipped to communicate with their patients about herbs for specific conditions. Other solutions include continuing education programmes, the availability of reputable references such as pharmacopoeias, placing books on herbal medicine in hospital libraries and integrating herbal medicine studies into medical school curricula. Furthermore, patient education via social media or medical staff and the availability of integrative clinics in hospitals would encourage patients to discuss their herbal use with doctors. These measures may all help in narrowing the communication and knowledge gap.

Furthermore, there was no significant relation between physician's characteristics and the likelihood of recommending herbal usage to patients. A study conducted in the USA evaluating the attitudes of physicians at an academic medical centre towards CAM, reported that physicians under 46 years were more inclined to accept its potential value and 30\% believed that knowledge of CAM practices would lead to better patient outcomes [37]. In a study conducted in the USA to determine general attitudes and approaches to CAM among obstetric and gynaecology patients and physicians, the latter declared that they need to be aware of recent updates about herbal medicine as they are relevant to patient health [36]. Furthermore, half of the participants in our study were neutral or against referring patients to a herbal medicine clinic if one is available, which is different to a study in the USA indicating that healthcare providers are more likely to refer patients to CAM or herbal medicine practitioners [18]. 


\section{Strength and limitations}

One of the strengths of this study is that it investigates both diabetic patients and their doctors at the same time to illustrate clearly the relationship between them and clarify the current situation regarding the use of herbal medicine for diabetes. The study has certain limitations including generalization from a convenient sample size that was collected from hospitals in one region. However, these findings should not be generalized to the wider population. In addition, the interview-based questionnaire, the method of collecting data from the diabetic patients, may have resulted in interview bias, although it is accepted as a legitimate scientific method. However, most of the patients would not have been able to fill in a self-administered questionnaire as they suffer from complications due to their disease. Regarding healthcare professionals, it was not possible to obtain the exact number of physicians in KSA to calculate sample size precisely and they were the only category included in this study, but broadening the sample to include other healthcare providers such as pharmacists and nurses would make it representative for all healthcare professionals.

\section{Conclusion}

This research revealed that managing blood glucose levels with herbal medicine is common practice among diabetic patients and many patients did not disclose this to their doctors, indicating a gap or miscommunication in their relationship which has an impact on patient health. Thus, doctors need to ask patients about herbal usage, encourage them to talk about it, and be aware of the most recent updates in this rapidly changing field in order to be able to give sound advice on the proper use of herbs for diabetes management. In addition, perception about herb effectiveness and safety is high, suggesting that the general public needs to be educated about the possible harms caused by self-medicating with herbs. The Ministry of Health as well as individual healthcare providers need to consider how current media channels may be used for this type of educational purpose. More government-based research and educational programmes about herbs for diabetes are needed in KSA to maximize the benefits and minimize the side effects.

\section{Abbreviations \\ CAM: Complementary and alternative medicine; IDF: International Diabetes Federation; IRB: Institutional Review Board; KAP: Knowledge, attitude and practice; WHO: World Health Organization}

\section{Acknowledgements}

We would like to thank the staff at $\mathrm{MOH}$ for clinical and administrative assistance and patients for contributing in this study.

\section{Authors' contributions}

AA, Study manager, study design, data analysis and manuscript preparation. GA, data collection and analysis. HB, KA, OK, SJ and SM, data collection. FA, manuscript preparation. All authors have read the submitted manuscript and approve the submission.

Funding

No funding sources were provided to complete this research.

\section{Availability of data and materials}

The data used and analyzed during in this study are available from the corresponding author on reasonable request.

\section{Ethics approval and consent to participate}

This study approved by the Ethics Committee, Ministry of Health, $(\mathrm{H}-02-$ K076-1811-063, 2018). Written informed consent for participation was obtained.

\section{Consent for publication}

Not applicable.

\section{Competing interests}

The authors declare that they have no competing interests.

\section{Author details}

'Department of Pharmacognosy, Pharmacy College, Umm Al-Qura University, Makkah 21955, Saudi Arabia. ${ }^{2}$ Department of Clinical Pharmacy and Pharmacy Practice, College of Clinical Pharmacy, Imam Abdulrahman Bin Faisal University, Dammam, Saudi Arabia.

Received: 14 October 2019 Accepted: 12 February 2020

Published online: 28 February 2020

\section{References}

1. AlQathama A. Natural products \& complementary medicines: where are we up to? Br J Pharm. 2016;1:1.

2. $\mathrm{NCClH}$. Exploring the science of complementary and alternative medicine: National Center for Complementary and Integrative Health (NCCIH); 2017.

3. Rashrash M, Schommer JC, Brown LM. Prevalence and predictors of herbal medicine use among adults in the United States. J Patient Exp. 2017:4(3): 108-13.

4. Judith O, ljeoma O, Ekere K, Isaac A, Christianah I, Olubunmi O, et al. Popularity and customer preferences for herbal medicines in Nigeria: a questionnaire based survey. Humanit Soc Sci Lett. 2016;4(3):69-76.

5. WHO. WHO global report on traditional and complementary medicine. 2019.

6. Benzie IF, Wachtel-Galor S. Herbal medicine: biomolecular and clinical aspects: CRC press; 2011

7. Mahomoodally MF. Traditional medicines in Africa: an appraisal of ten potent African medicinal plants. Evid Based Complement Alternat Med. 2013;14:1.

8. Ekor M. The growing use of herbal medicines: issues relating to adverse reactions and challenges in monitoring safety. Front Pharmacol. 2014;4:177.

9. El Nimr N, Wahdan I, Wahdan A, Kotb R. Self-medication with drugs and complementary and alternative medicines in Alexandria, Egypt: prevalence, patterns and determinants. EMHJ-East Mediterr Health J. 2015;21(4):256-65.

10. Al Akeel MM, Al Ghamdi WM, Al Habib S, Koshm M, Al OF. Herbal medicines: Saudi population knowledge, attitude, and practice at a glance. J Family Med Prim Care. 2018;7(5):865-75

11. Alrowais NA, Alyousefi NA. The prevalence extent of complementary and alternative medicine (CAM) use among Saudis. Saudi Pharm J. 2017;25(3): 306-18.

12. Zheng Y, Ley SH, Hu FB. Global aetiology and epidemiology of type 2 diabetes mellitus and its complications. Nat Rev Endocrinol. 2017;14:88.

13. Medagama $A B$, Bandara R. The use of complementary and alternative medicines (CAMs) in the treatment of diabetes mellitus: is continued use safe and effective? Nutr J. 2014;13:102.

14. WHO. Diabetes: WHO; 2018 [Available from: https://www.who.int/newsroom/fact-sheets/detail/diabetes.

15. Kesavadev J, Saboo B, Sadikot S, Das AK, Joshi S, Chawla R, et al. Unproven therapies for diabetes and their implications. Adv Ther. 2017;34(1):60-77.

16. Grossman LD, Roscoe R, Shack AR. Complementary and alternative medicine for diabetes. Can J Diabetes. 2018;42:S154-S61. 
17. Brown J, Cooper E, Frankton L, Steeves-Wall M, Gillis-Ring J, Barter W, et al. Complementary and alternative therapies: survey of knowledge and attitudes of health professionals at a tertiary pediatric/women's care facility. Complement Ther Clin Pract. 2007;13(3):194-200.

18. Zhang Y, Peck K, Spalding M, Xu T, Ragain M. A study to examine the attitudes, knowledge, and utilization of CAM by primary care professional in West Texas. Complement Ther Med. 2010;18(6):227-32.

19. Federation ID. IDF MENA Members 2017.

20. Sakpal TV. Sample size estimation in clinical trial. Perspect Clin Res. 2010;1(2): 67-9.

21. Scanlan JC. Pharmaceutical care of cancer patients: a multidisciplinary perspective: University of London; 2002.

22. Amaeze OU, Aderemi-Williams Rl, Ayo-Vaughan MA, Ogundemuren DA, Ogunmola DS, Anyika EN. Herbal medicine use among type 2 diabetes mellitus patients in Nigeria: understanding the magnitude and predictors of use. Int J Clin Pharm. 2018:40(3):580-8.

23. Mekuria AB, Belachew SA, Tegegn HG, Ali DS, Netere AK, Lemlemu E, et al. Prevalence and correlates of herbal medicine use among type 2 diabetic patients in teaching Hospital in Ethiopia: a cross-sectional study. BMC Complement Altern Med. 2018;18(1):85.

24. Alsanad S, Aboushanab T, Khalil M, Alkhamees OA. A descriptive review of the prevalence and usage of traditional and complementary medicine among Saudi diabetic patients. Scientifica. 2018;2018:1-10.

25. Alalami U, Saeed KA, Khan MA. Prevalence and Pattern of Traditional and Complementary Alternative Medicine Use in Diabetic Patients in Dubai, UAE. Arab J Nutr Exerc (AJNE). 2017:2017:10

26. Peltzer $\mathrm{K}$, Pengpid $\mathrm{S}$. The use of herbal medicines among chronic disease patients in Thailand: a cross-sectional survey. J Multidiscip Healthc. 2019;12: 573.

27. $\mathrm{H}-\mathrm{y} \mathrm{C}$, Wallis $\mathrm{M}$, Tiralongo $\mathrm{E}$. Use of complementary and alternative medicine among people living with diabetes: literature review. J Adv Nurs. 2007:58(4):307-19.

28. Dahlgren JP, Ehrlén J. Linking environmental variation to population dynamics of a forest herb. J Ecol. 2009;97(4):666-74.

29. Ching SM, Zakaria ZA, Paimin F, Jalalian M. Complementary alternative medicine use among patients with type 2 diabetes mellitus in the primary care setting: a cross-sectional study in Malaysia. BMC Complement Altern Med. 2013;13(1):148.

30. Alrowais NA. Herbal medicine in the treatment of diabetes mellitus. Saudi Med J. 2002;23(11):1327-31.

31. Shih C-C, Liao C-C, Su Y-C, Tsai C-C, Lin J-G. Gender differences in traditional Chinese medicine use among adults in Taiwan. PLoS One. 2012;7(4):e32540.

32. Ithan M, Demir B, Yüksel S, Çataklı SA, Yıldız RS, Karaman O, et al. The use of complementary medicine in patients with diabetes. North Clin Istanb. 2016; 3(1):34-8.

33. Frawley J, Adams J, Broom A, Steel A, Gallois C, Sibbritt D. Majority of women are influenced by nonprofessional information sources when deciding to consult a complementary and alternative medicine practitioner during pregnancy. J Altern Complement Med. 2014;20(7):571-7.

34. Al-Eidi S, Tayel S, Al-Slail F, Qureshi NA, Sohaibani I, Khalil M, et al. Knowledge, attitude and practice of patients with type 2 diabetes mellitus towards complementary and alternative medicine. J Integr Med. 2016;14(3): 187-96.

35. Ali-Shtayeh MS, Jamous RM, Jamous RM. Complementary and alternative medicine use amongst Palestinian diabetic patients. Complement Ther Clin Pract. 2012;18(1):16-21

36. Furlow ML, Patel DA, Sen A, Liu JR. Physician and patient attitudes towards complementary and alternative medicine in obstetrics and gynecology. BMC Complement Altern Med. 2008:8(1):35.

37. Wahner-Roedler DL, Vincent A, Elkin PL, Loehrer LL, Cha SS, Bauer BA. Physicians' attitudes toward complementary and alternative medicine and their knowledge of specific therapies: a survey at an academic medical center. Evid Based Complement Alternat Med. 2006;3(4):495-501.

\section{Publisher's Note}

Springer Nature remains neutral with regard to jurisdictional claims in published maps and institutional affiliations.

\section{Ready to submit your research? Choose BMC and benefit from:}

- fast, convenient online submission

- thorough peer review by experienced researchers in your field

- rapid publication on acceptance

- support for research data, including large and complex data types

- gold Open Access which fosters wider collaboration and increased citations

- maximum visibility for your research: over $100 \mathrm{M}$ website views per year

At BMC, research is always in progress.

Learn more biomedcentral.com/submissions 